\title{
MORPHO-PHYSIOLOGICAL TRAITS OF SOYBEAN AS AFFECTED BY DROUGHT
}

\author{
I.A. Rima ${ }^{1}$, M.A. Mannan ${ }^{1}$, M.A.A. Mamun ${ }^{1}$ and Z.U. Kamal ${ }^{2}$ \\ ${ }^{1}$ Department of Agronomy, ${ }^{2}$ Department of Soil Science \\ Bangabandhu Sheikh Mujibur Rahman Agricultural University, Gazipur-1706, Bangladesh \\ *Corresponding E-mail: mannanbsmrau@yahoo.com
}

(Received: 17 December 2019, Accepted: 27 February 2020)

Keywords:Morpho-physiology, water stress, soybean

\begin{abstract}
An experiment was conducted to study the effects of water deficit stress on morphophysiological parameters in soybean plant in pots at the Department of Agronomy, Bangabandhu Sheikh Mujibur Rahman Agricultural University, Gazipur, Bangladesh during February to June, 2018. Seven soybean genotypes namely,i) G00081 ii) G00056 iii) Shohag iv) G00078 v) G00137 vi) G00035 and vii) G00060 were grown in two watering regimes viz. control ( $80 \%$ of the field capacity) and water deficit stress $(50 \%$ of the field capacity). Morpho-physiological traits including plant height, number of leaf, relative water content, water saturation deficit, chlorophyll, proline, dry matter and yield were investigated. Results indicated that genotypic variability was found in water deficit stress tolerance in soybean. It was found that leaf of the genotype G00081 maintained higher water content, higher accumulation of prolineas well as less reduction of chlorophyll compared to other genotypes studied. Total dry matter accumulation and grain yield plant ${ }^{-1}$ was also higher in this genotype. Genotype G00081 also showed relatively higher water deficit stress tolerance. On the contrary, G00035 was found to be susceptible showing lower yield. Higher water deficit stress tolerance in G00081 was attributed to higher relative leaf water and chlorophylls with accumulation of higher amount of proline.
\end{abstract}

\section{Introduction}

Plant experiences water deficit stress either when the water supply to roots becomes difficult or the transpiration rate becomes very high. Water deficit stress inhibits the photosynthesis of plants, causes changes in chlorophyll contents and damages the photosynthetic apparatus (Escuredoet al., 1998) which ultimately reduces growth promoters (Prabaet al., 2009). Under water deficit stress, cell expansion of leaf is reduced due to low turgor which is controlled by the processes related to cellular water uptake and cell wall extension that results in decreased leaf area and weight (Cramer et al., 1993). The yield and biochemical composition of a plant mainly depends on growth conditions, which is markedly affected by water availability (Pacliket al., 1996). Soybean is inherently more stress tolerant (Singh et al., 2003) than other legume crops but it still suffers considerable damage due to water deficit stress in different regions where rainfall is scanty or irregular and irrigation facility is unavailable. Water stress as a key abiotic limiting factor for soybean production can cause soybean yield reduction up to $40 \%$ or even more (Pathanet al., 2007). Mechanisms of water deficit stress tolerance, especially at low water stress involve processes at the cellular level, the most important being osmotic adjustment and protection of the membrane system. Osmotic adjustment is the decrease of osmotic potential by the active accumulation of organic as well as inorganic solutes within the cells. High concentrations of inorganic ions become detrimental to cellular metabolism and must be sequestered in the vacuole. In order to keep osmotic balance, specific types of organic molecules (such 
as soluble sugars, betains, proline etc.) are accumulated in the cytoplasm. Those compounds protecting plants against stresses by cellular adjustment through the protection of membranes integrity and enzymes stability (Farooq et al., 2009) are termed as compatible solutes asthey can be accumulated in high concentrations without impairing normal physiological function. The present study was undertaken to analyze the changes of morpho-physiological parameters that are associated with water deficit stress tolerance of soybean.

\section{Materials and Methods}

The experiment was conducted in the Department of Agronomy, Bangabandhu Sheikh Mujibur Rahman Agricultural University (BSMRAU), Gazipur during February to June, 2018. It was located at $24.09^{0} \mathrm{~N}$ latitude and $90.26^{\circ} \mathrm{E}$ longitudes at an elevation of $8.4 \mathrm{~m}$ from the mean sea level. The soil of the pot was fertilized uniformly with $0.9,0.8$ and $0.8 \mathrm{~g}$ urea, triple super phosphate and muriate of potash corresponding to $160-150-150 \mathrm{~kg}$ urea, triple super phosphate and muriate of potash per hectare, respectively. Ten healthy seeds of seven soybean genotypes namely i) G00081 ii) G00056 iii) Shohag iv) G00078 v) G00137 vi) G00035 and vii) G00060 were grown in each pot in 15 February, 2018. Light irrigation was given by using the water can to ensure uniform germination of seeds after sowing. Two water regimes i) Control (80\% field capacity) ii) Water deficit stress (50\% field capacity) were maintained from $1^{\text {st }}$ trifoliate (14 days after germination) stage to maturity using portable digital moisture meter (POGO Soil Sensor II, Stevens, USA). Different intercultural operations were done as and when were necessary. Data on plant height, number of leaf / plant, dry weight of leaf, stem and total dry matter were collected at 40 days after drought imposition. Leaf chlorophyll, proline and water relations traits were measured at flowering stage. Yield and yield contributing data were collected after harvest. The recorded data were statistically analyzed by "MSTAT-C" software to examine the significant variation of the results due to different treatments. The treatment means were compared by Least Significance Difference (LSD) test at 5\% level of significance (Gomez and Gomez, 1984).

\section{Results and Discussion}

At 40 days after drought imposition, the plant height at control was the highest in Shohag $(156 \mathrm{~cm})$, while the lowest was in Gooo60 $(55 \mathrm{~cm})$. Under water stress condition the highest plant height was recorded with G00078 $(110.33 \mathrm{~cm})$ and the lowest was in G00060 $(46.33 \mathrm{~cm})$. Relative (per cent of control) plant height of the genotypes ranged from $64 \%$ to $94 \%$. Highest relative plant height was obtained from genotype G00056 (94\%) which was then followed by G00060 (84\%), G00137 (81\%), G00078 (78\%), G00035 (77\%), and G00081 (72\%); and it was lowest in Shohag (64\%) (Figure 1).Plant height reduction due to water stress was lower in Gooo56 (16\%), while that was higher in Shohag (36\%). The lower height intheplants under water deficiency occurred, probably duetheABA action, in whichitisproduced inthecellsunder water stress condition and this way inhibited the cell divisionand / or DNA synthesis which was supported by Wang et al. (1998. Similarresults ontheheightreduction in plantsunder waterstressweredescribed byMartinez etal. (2004)studyingAtriplexhalimus, aswellasLacerdaetal. (2001)workingwithgenotypes ofSorghumbicolorunder water stress in saline soil. 


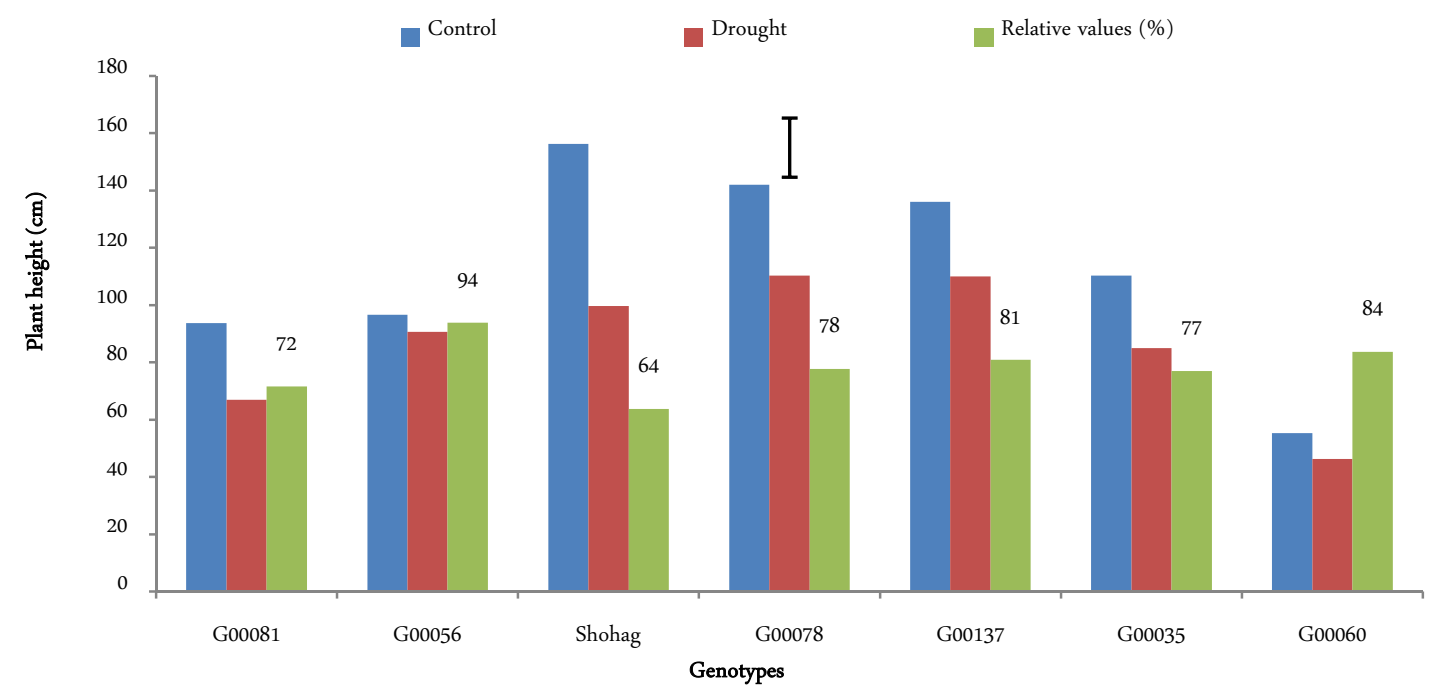

Fig. 1. Effect of drought on plant height of soybean at 40 days after drought imposition. Bar indicate LSD (0.05).

Number of leaf of different soybean genotypes varied significantly due to water deficit stress imposition (Figure 2). At 40 days after drought imposition, the number of leaves both in control and water stress treatments was recorded to be the highest in G000137 and Shohag, respectively. Relative number of leaves of the genotypes ranged from 53 to $81 \%$ at water stress condition. Highest relative number of leaf was obtained from G00081 (81\%), followed by G00056 (71\%), G00060 (67\%), G00035 $(65 \%)$ and Shohag (58\%) and it was lowest in G00078 (53\%). The reduction in the number of leaves due to water stress was lowest inG00081 (19\%), while highest in G00078 (67\%). The smallernumberofleavesshownintheplants under waterstresswasdue to the dropin leaf relative water content (LRWC). Similar result was also reported by Uddin et al. (2013) in mungbean (VignaradiataL.) plant.

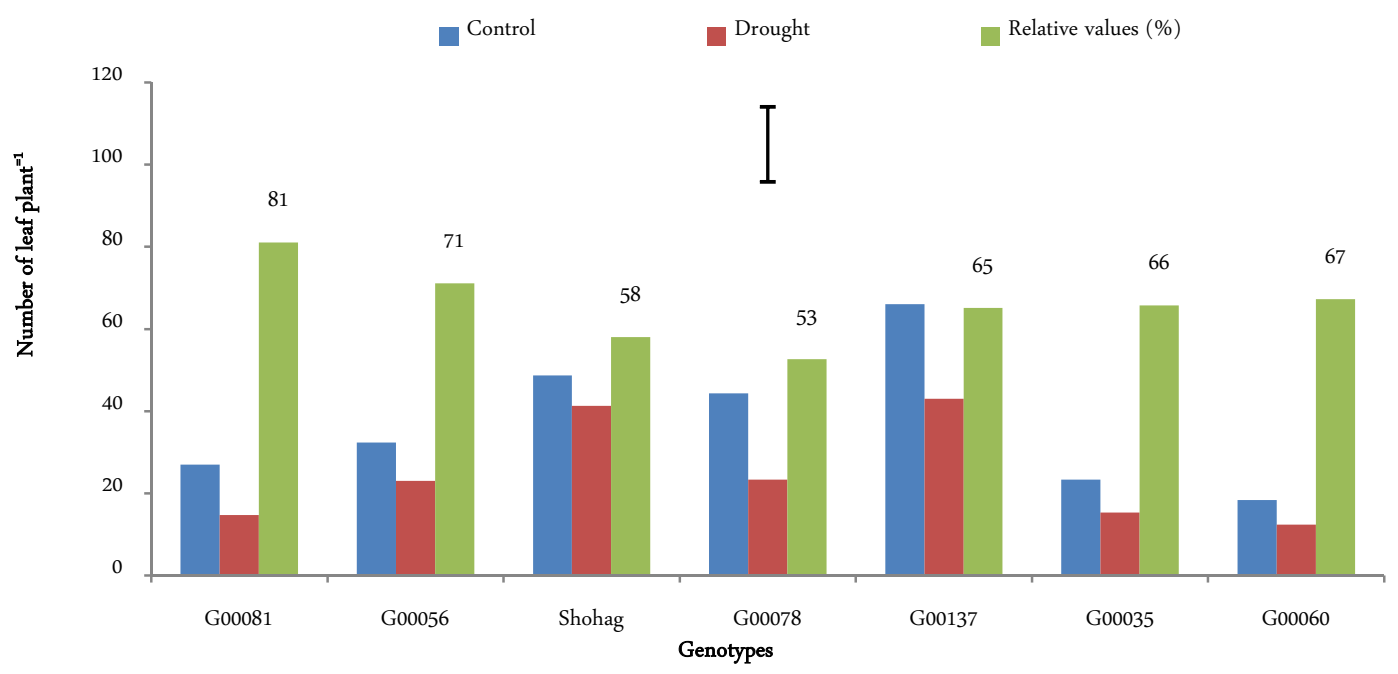

Fig. 2. Effect of drought on number of leaf of soybean at 40 days after drought imposition. Bar indicate $\operatorname{LSD}(0.05)$. 
They found significant effect of water stress on the number of leaves per plant at 30, 75 and 90 DAS (Days after sowing). The result showed that as the water stress increased, the number of leaves per plant decreased indicating that water stress had a direct effect on senescence and dropped out the leaves.

Effect of water deficit stress on leaf dry matter production was statistically significant (Figure 3). The highest leaf dry matter under control was recorded in G00137 (19.40 g), followed by G00078 (17.30 g), Shohag (16.09 g), G00081 (11.70 g), G00056 (10.85 g) and G00035 (8.18 g) while the lowest was found in G00060 (2.40 g). On the other hand, under water deficit stress condition Shohag produced the highest leaf dry matter (10.34 g), followed by G00137 (8.30 g), G00056(5.88 g), G00078 (5.31 g), G00035 (4.01 g) and G00081 (3.66 g); and the lowest was recorded from G00060 (2.59 g). Relative leaf dry matter of the genotypes ranged from $43 \%$ to $73 \%$. Highest relative leaf dry matter was obtained from G00081 (73\%) and it was lowest in G00137 (43\%). The reduction of the leaf dry matter due to water stress was lower in G00081 (27\%), while that was higher in G00137 (57\%). Khan (2014) reported that leaf traits like leaf number, leaf area and its dry weight of the soybean genotypes were sharply decreased when the plants were exposed to water and salt stress conditions.Fentaet al. (2014) also found significant differences in leaf dry matter, stem dry matter and shoot dry matter in wellwatered and drought conditions. Leaf dry weight was reduced in water stressed cotton plants as was reported by Pace et al. (1999).

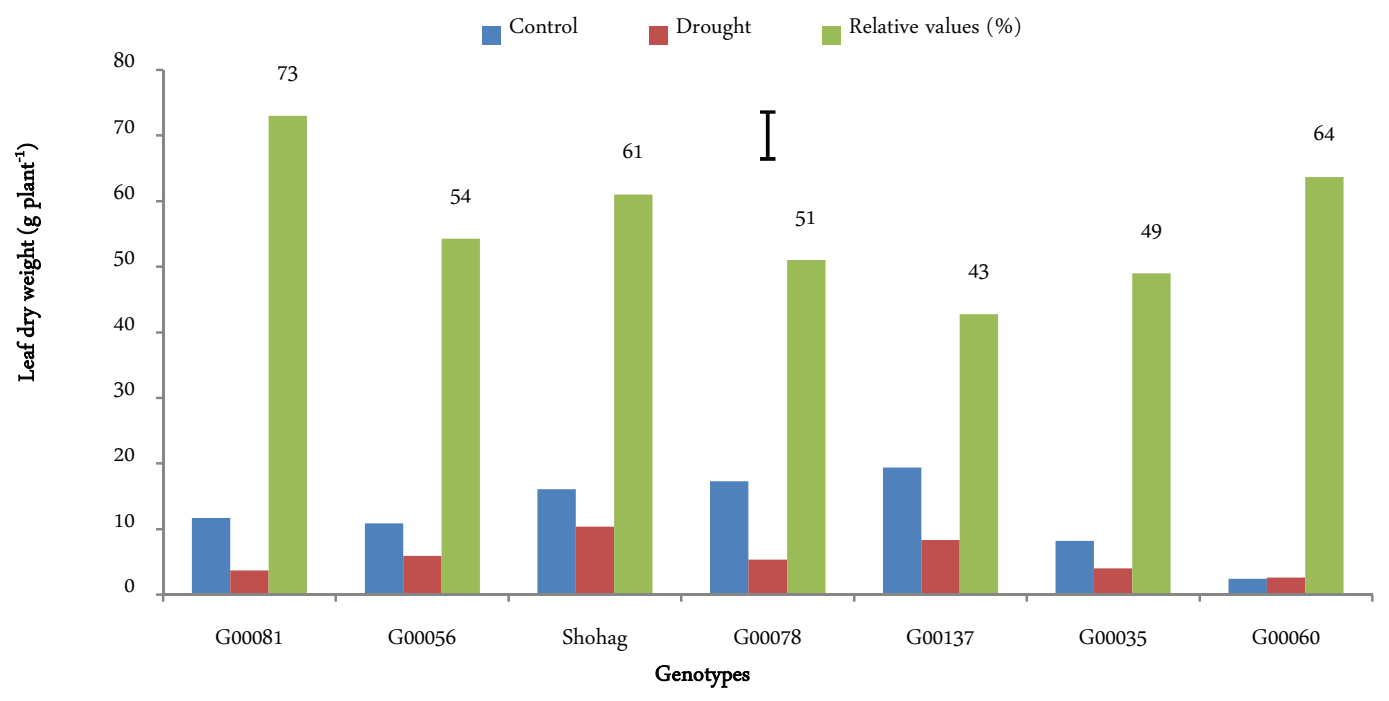

Fig. 3. Effect of drought on leaf dry weight of soybean at 40 days after drought imposition. Bar indicate LSD (0.05).

Petiole dry weight of soybean genotypes was affected significantly due to water stress (Figure 4). The highest petiole dry weight under control was recorded in G00137 (10.40 g), followed by Shohag (7.54 g), G00078 (5.23 g), G00056 (5.15 g), G00081 (4.51 g) and G00035 (2.33 g); whereas the lowest in G00060 (1.18 g). On the other hand, under water deficit stress condition G00137 produced the highest petiole dry matter $(3.46 \mathrm{~g})$ while the lowest was recorded from G00060 (0.76 g). Relative petiole dry matter of the genotypes ranged from $33 \%$ to $53 \%$. Highest relative leaf dry matter was obtained from G00060 (53\%) and it was lowest in G00137 (33\%). The reduction of the leaf dry matter due to water stress was lower in G00061 (47\%), while that was higher in G00137 (67\%). 


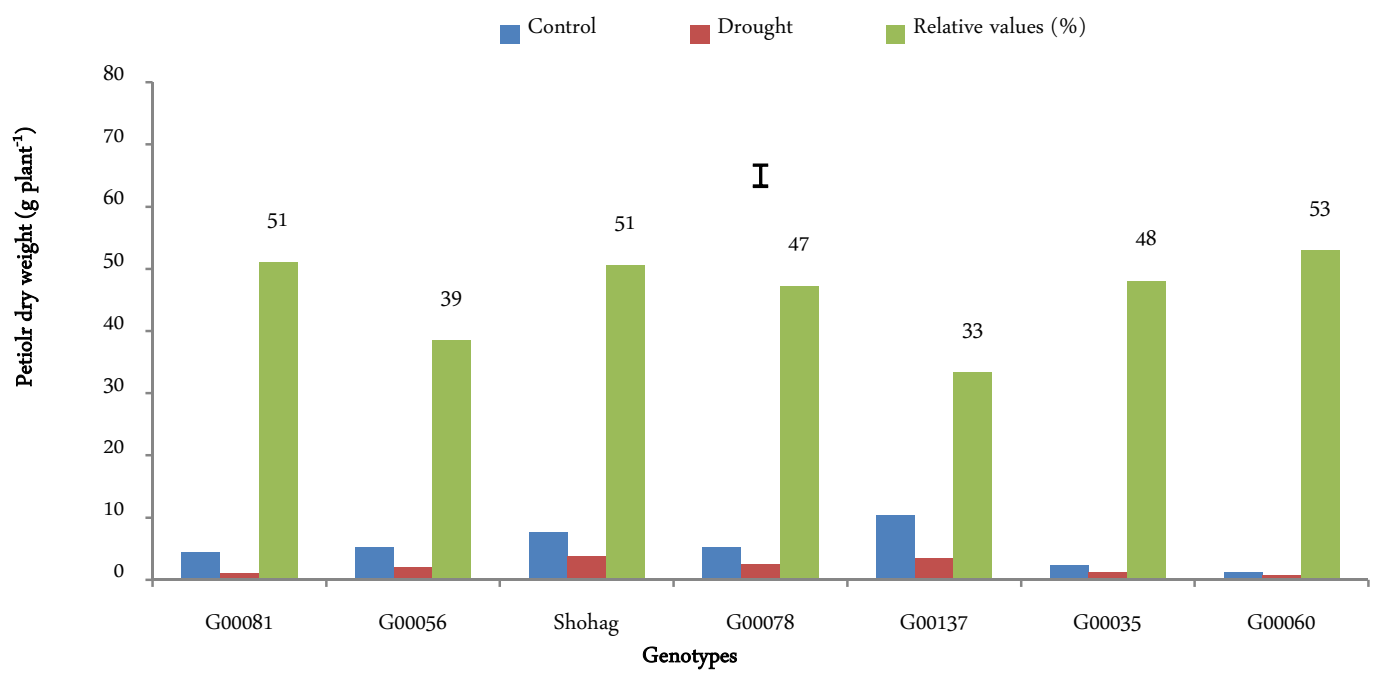

Fig. 4. Effect of drought on petiole dry weight of soybean at 40 days after drought imposition. Bars indicate LSD 0.05).

The effect of water deficit stress on stem dry matter production was statistically significant (Figure5). The highest stem dry matter under control condition was recorded in G00137 (18.17 g) which was followed by G00078 (17.49 g), Shohag (15.18 g), G00056 (10.18 g), G00035 (6.04 g) and G00081 $(3.93 \mathrm{~g})$; and the lowest was found in G00060 (2.03 g). On the other hand, under water stress condition G00078 produced the highest stem dry matter $(9.06 \mathrm{~g})$ while the lowest was recorded from G00060 $(1.36 \mathrm{~g})$. Relative stem dry matter of the genotypes ranged from $28 \%$ to $65 \%$ at water deficit conditions showing the highest with G00081 (65.03\%) which was then followed by G00060 (63\%), G00078 (52\%), G00035 (50\%), Shohag (44\%) and G00137 (42\%) while it was lowest in BARI Soybean-5 $(36.72 \%)$.

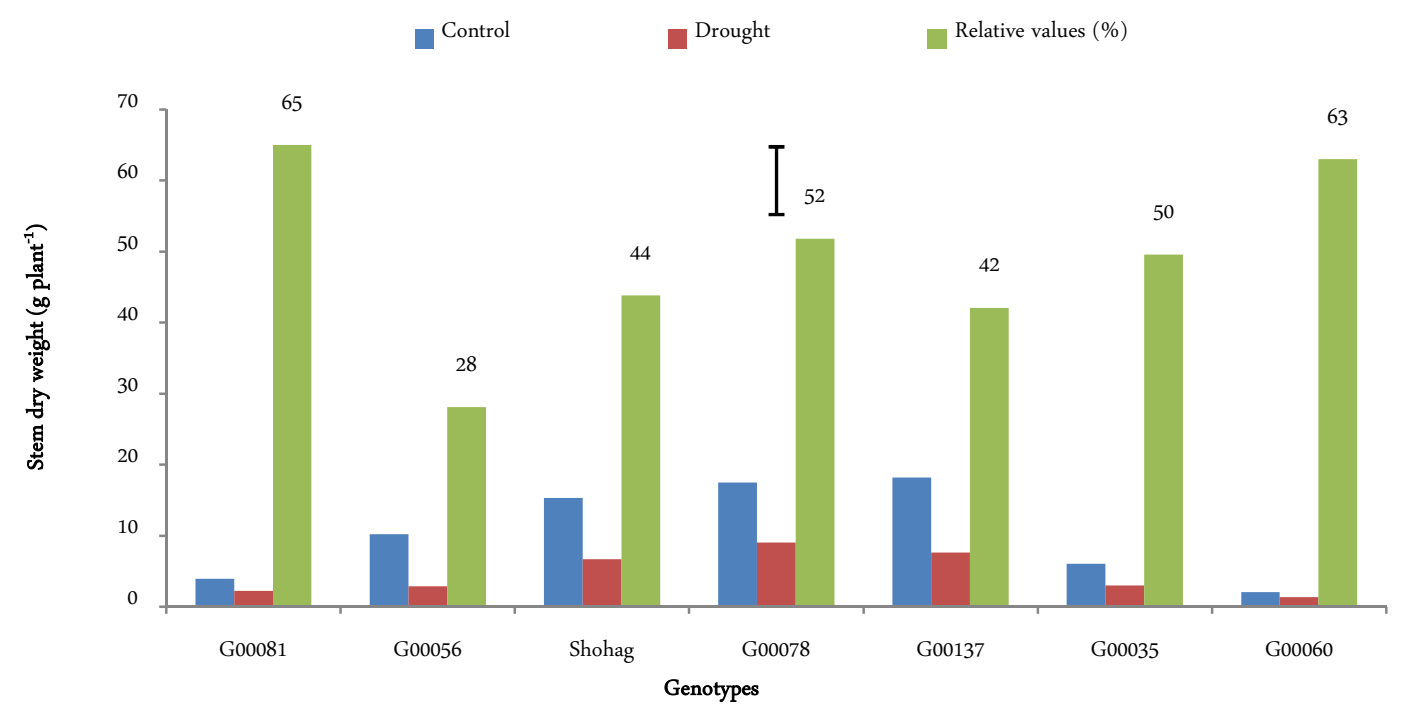

Fig. 5. Effect of drought on stem dry weight of soybean at 40 days after drought imposition. Bars indicate LSD (0.05). 
The reduction of the stem dry matter due to water stress was lower in Binasoybean-1 (52.97\%), while that was higher in BARI Soybean-5 (63.28\%). Canavaret al. (2014) reported thatmorphological components such as leaf stem and total dry weight of sunflower cultivars were found to be mostly influenced by water stress. The lowest reduction in terms of leaf, stem and total dry weight was obtained from the cultivar that grown under well-watered condition as compared with the other sunflower cultivars under the water stress. Moussa (2011) reported that water deficits decreased the dry weight of stems and leaves; total biomass and seed yield of soybean genotypes, but did not affect the dry weight of roots.

Pod dry weight of soybean genotypes was affected significantly due to water stress (Figure 6). The highest pod dry weight under control was recorded in G00035 (15.30 g), followed by G00056 (12.08 g), G00060 (11.79 g), G00081 (10.94 g), G00137 (10.67 g) and Shohag(9.42 g) the lowest was found in G00078 (7.66 g). On the other hand, under water deficit stress condition G00035 produced the highest pod dry matter $(9.55 \mathrm{~g})$ and the lowest was recorded from G00137 (4.78 g). Relative pod dry matter of the genotypes ranged from $41 \%$ to $77 \%$ which was the highest in G00081 (77\%) and lowest in G00056 $(41 \%)$. The reduction of the pod dry matter due to water stress was lower in G00081 (33\%), while that was higher in G00056 (69\%).

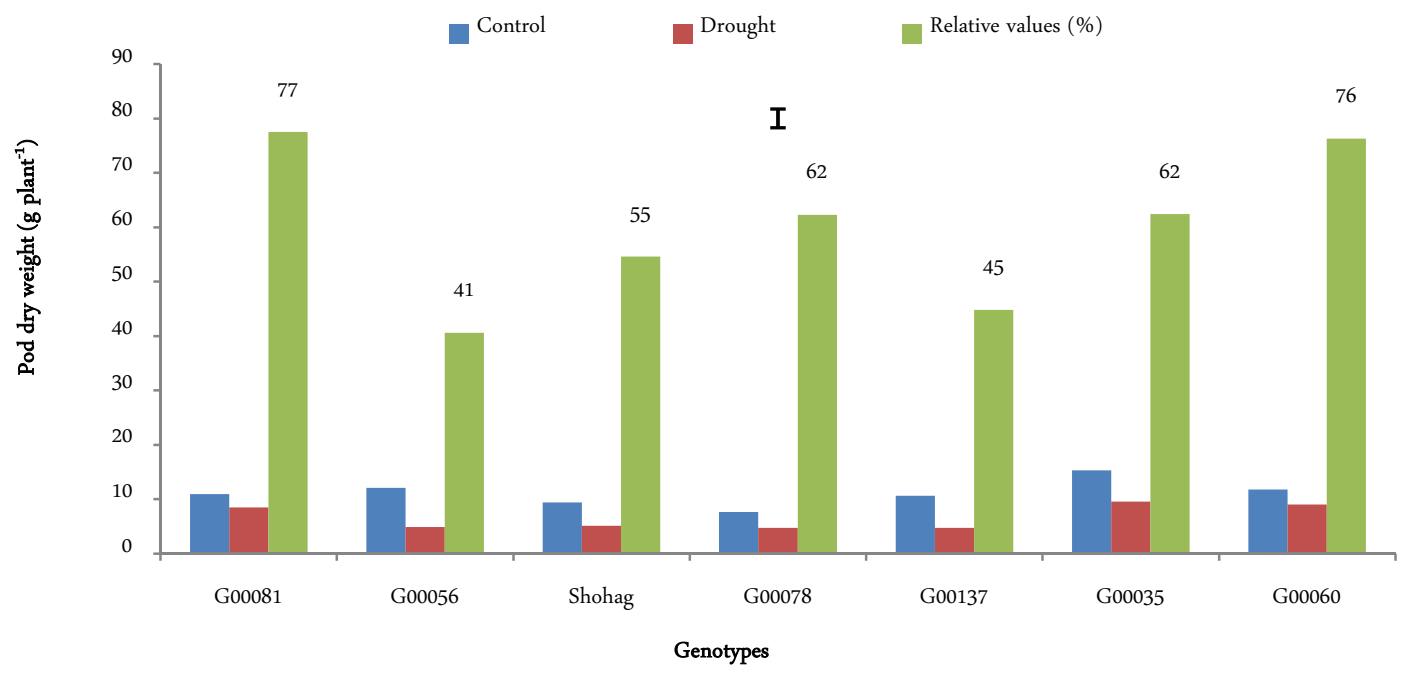

Fig. 6. Effect of drought on pod dry weight of soybean at 40 days after drought imposition. Bar indicate $\operatorname{LSD}(0.05)$.

The effect of water deficit stress on total dry matter production was statistically significant (Table Figure 7). The highest total dry matter under control was recorded in G00137 (58.64 g), followed by Shohag (49.34 g), G00078 (47.7 g), G00056 (38.26 g), G00035 (32.19 g) and G00081 (22.09 g) and the lowest was found in G00060 (17.42 g). Shohag produced the highest total dry matter $(25.99 \mathrm{~g})$ and the lowest was recorded from G00060 (12.52 g). Relative total dry matter of the genotypes ranged from $41 \%$ to $71 \%$ at water deficit conditions. Highest relative total dry matter was obtained from G00081 $(72 \%)$ and lowest in G00056 (41\%). The reduction of the total dry matter due to water stress was lower in G00081 (28\%), while that was higher in G00056 (59\%). Water stresscausedsignificantdecreasein plant growth. These results are in harmony with AbassandMohamed(2011)who reportedthatthe plant growthparametersof commonbean(shootand root length, fresh and dry weights of shoots and roots)decreasedsignificantly withincreasingdrought stressascomparedwithcontrolplants. Suchdecline inshootand rootgrowthin response todroughtmight be due to either decrease in cell elongation, cell turgor, cell volume and eventually cell growth (Banonetal., 
2006), and/orduetoblockingupof

xylemandphloemvesselshinderingphotosynthetictranslocation(Lavisoloand Schuber,1998). Water stress inhibits dry matter production largely through its inhibitory effects on leaf expansion, leaf development and consequently reduced light interception (Nam et al., 1998).

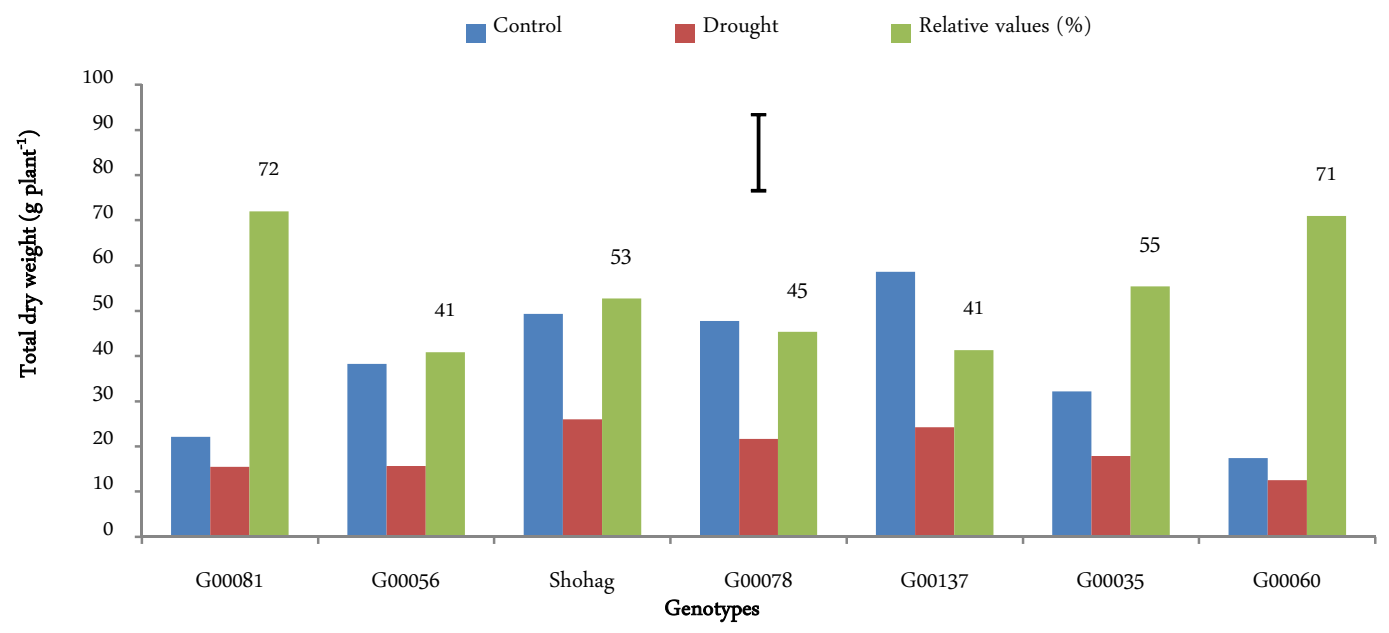

Fig. 7. Effect of drought on total dry weight of soybean at 40 days after drought imposition. Bar indicate LSD (0.05).

Relative water content in leaf indicates the water status in leaf. It was found that under water stress condition leaf moisture decreased significantly (Figure 8). Highest relative water content was found under control in the leaves of G00035 (89.4\%) followed by G00081 (86.38\%), Shohag (85.86\%), G00056 (83.12\%), G00060 (81.09\%) and G00078 (63.9\%); and it was lowest in G000137 (61.02\%). But under drought condition the highest relative water content was observed in genotype G00056 $(75.18 \%)$ and the lowest was in G00078 (38.09\%).

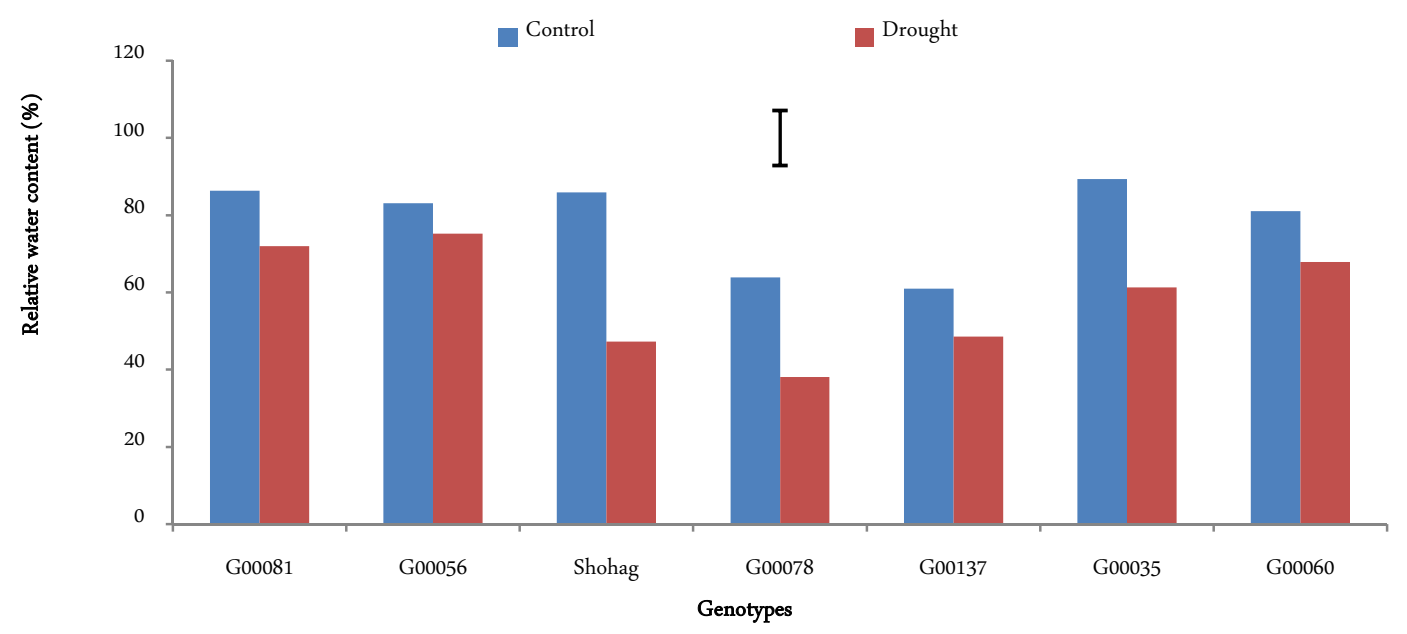

Fig. 8. Effect of drought on relative water content of soybean at flowering stage. Bar indicate LSD (0.05).

Water saturation deficit increased in drought condition in all the genotypes (Figure 9). Highest water deficit was found in G00078 (38.04\%) and it was lowest in G00081 (14.17\%). 
VeluandPalanisami(2002) reportedthat waterstresssignificantly reducedrelativewatercontentoftheplant. Nayyarand Gupta (2006) reported that the decrease in the RWC in response to drought stress has been noted in a wide variety of plants saying that when leaves were subject to water stress, leaves exhibited large reductions in RWC and water potential. Siddique et al. (2001) found that exposure of plants to water stress substantially decreased the leaf water potential, relative water content and transpiration rate with a concomitant increase in leaf temperature.

The effect of water deficit stress on total chlorophyll of soybean genotypes was significant at 40 days after water stress imposition (Figure 9). The total chlorophyll in well watered condition was highest in G00060 (4.32 mgg ${ }^{-1}$ fresh weight of leaf) and it was lowest in Shohag (3.45 $\mathrm{mgg}^{-1}$ fresh weight of leaf). Drought stress decreased chlorophyll content in leaf of all the genotypes and it was highest in G00060 (3.43 $\mathrm{mgg}^{-1}$ fresh weight of leaf). It was reportedthatthis pigmentwassensitive toincreasingenvironmental stress(Terziet al., 2010). Thedecreaseintotalchlorophyllcontent mayhaveresultedfromadecreaseinleafwaterstatus inthesoybean.

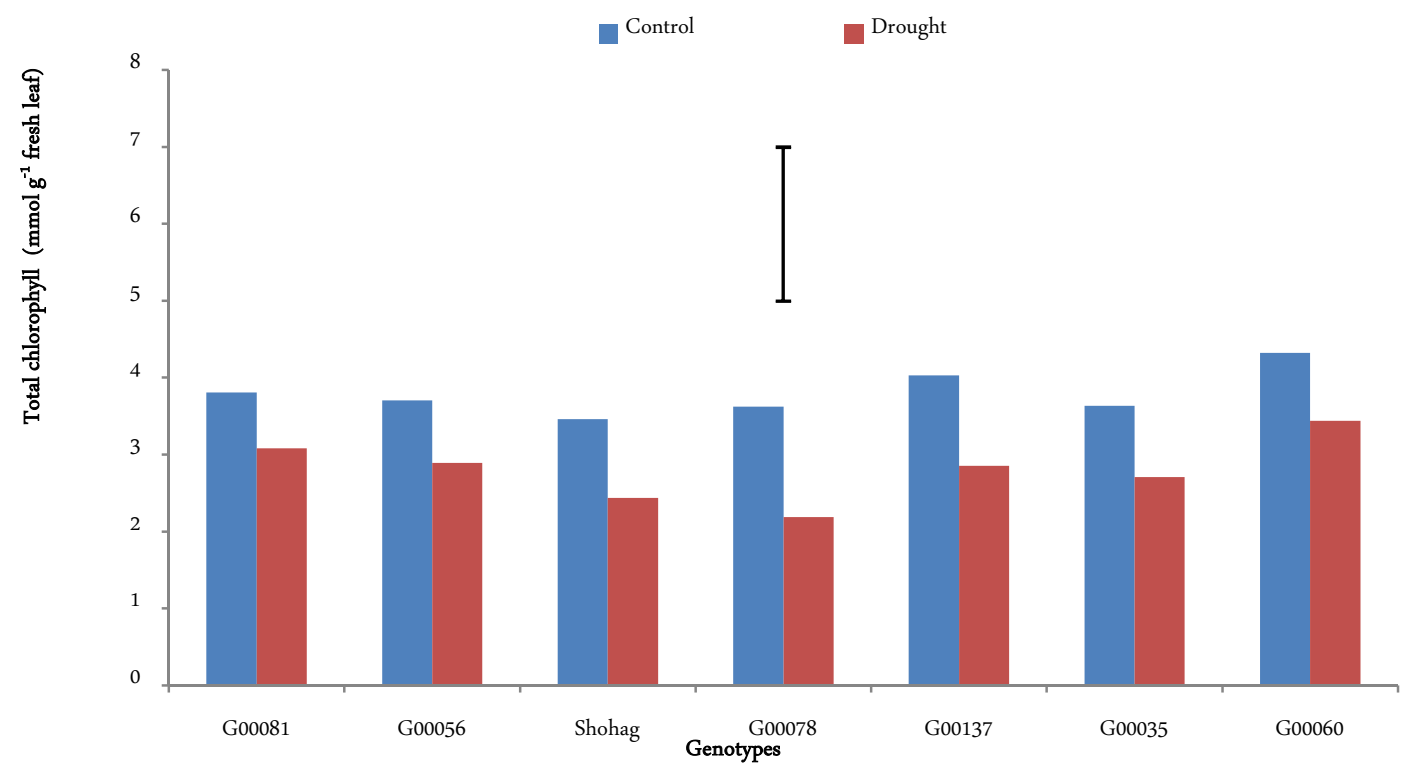

Fig. 9. Effect of drought on total chlorophyll of soybean leaf at flowering stage. Bar indicate LSD (0.05).

At 40 days after water deficit stress imposition, the highest amount of proline was recorded in G00081 (1.75 $\mu$ mole $\mathrm{g}^{-1} \mathrm{FW}$ leaf), followed by G00137 (1.73 $\mu$ mole $\mathrm{g}^{-1} \mathrm{FW}$ leaf), G00060 (1.69 $\mu \mathrm{mole}^{-1}$ FW leaf), G00078 (1.64 $\mu$ mole $\mathrm{g}^{-1} \mathrm{FW}$ leaf) and Shohag $\left(1.60 \mu\right.$ mole $\mathrm{g}^{-1}$ FW leaf) while the lowest was recorded in G00035 (1.38 $\mu$ mole $\mathrm{g}^{-1} \mathrm{FW}$ leaf). (Figure 10).Karimi and Mohseni (2013) found that drought stress significantly enhanced accumulation of proline in the leaf of all the cultivars viz., Shirale, Oscar, Con-II, Rainbow and $19 \mathrm{H}$ at flower initiation stage, and there were variability of proline accumulation among the genotypes. Hossain et al. (2014) found that progressive water restriction increased the concentration of proline in leaves of soybean genotypes. Nareshet al. (2013) reported similar increasing trend of proline content in genotypes under water deficit of Vigna radiate L. 


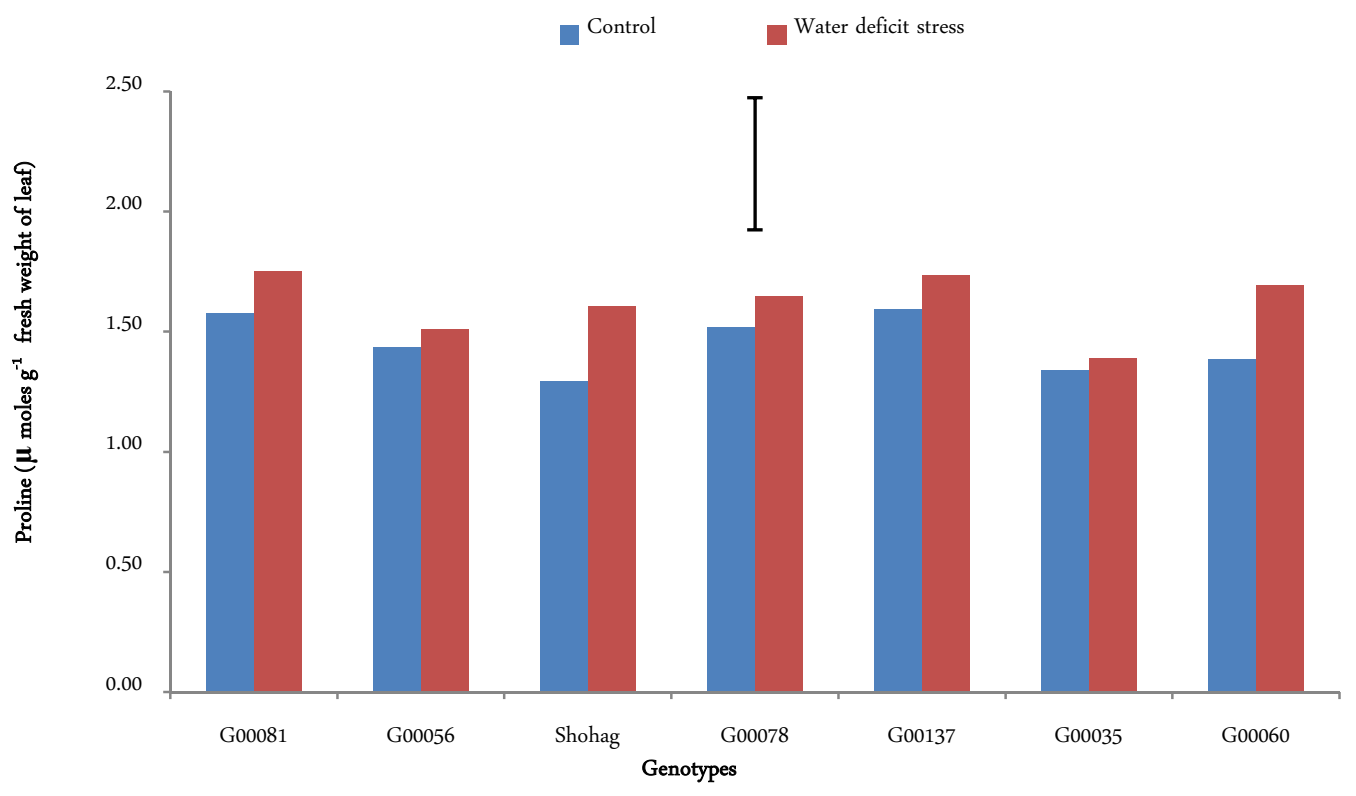

Fig. 10. Effect of water deficit stress on proline content at flowering stage.Bar indicate LSD (0.05).

The effect of water deficit stress on number of podsplant ${ }^{-1}$ was statistically significant (Table 1). The highest number of podsplant ${ }^{-1}$ under control was recorded in G00035 (104) and the lowest in G00081 (53). On the other hand, under water stress condition the genotype G00081 had the highest number of pods (47.67) while the lowest was recorded from G00137 (39). Relative number of podsplant ${ }^{-1}$ of the genotypes ranged from $43 \%$ to $90 \%$ at water deficit condition. Highest relative number of podsplant ${ }^{-}$ ${ }^{1}$ was obtained from G00081 (90\%), followed by G00060 (78\%), G00078 (53\%) and G00137 (45\%); and it was lowest in G00056 (43\%). The reduction of the number of podsplant ${ }^{-1}$ due to water stress was lower in G00081 (10\%), while that was higher in G00056 (57\%). Thesignificantreductioninnumberofthe harvested pods plant ${ }^{-1}$ underwaterstressmaybeattributed tothe abscissionofthereproductivestructures.Gwathmey andHall(1992)reportedsimilar results. Water stress caused by water shortage decreased pod number in pea as was reported by Duzdemiret al. (2009).

The effect of water deficit stress on number of seeds pod $^{-1}$ was statistically significant (Table 1). The highest number of seedspod ${ }^{-1}$ under control was recorded from G00081 (2.26) and the lowest was found in G00137 (1.42). On the other hand, under water stress condition,G00060 produced the highest number of $\operatorname{seedspod}^{-1}(1.73)$ while the lowest was recorded from G00137 (0.93). Relative number of seedspod $^{-1}$ of the genotypes ranged from 61 to $92 \%$ at water deficit conditions. Highest relative number of seedspod ${ }^{-1}$ was obtained from G00060 (92\%) which was then followed by G00056 (78\%), G00081 $(75 \%)$, and it was lowest in G00035 (59\%). The reduction of the number of seedspod ${ }^{-1}$ due to water stress was lower in G00060 (8\%), while that was higher in G00035 (41\%). Kazietal.(2002)showed thatnumber ofseedshead ${ }^{-1}$ reduced duetoa long droughtperiodinsunflower. Thereductionin numberof seed $\operatorname{pod}^{-1}$ andseedsizeunder water stress treatmentsmay beattributed to the limitationof dry matterpartitioning tothereproductivesinkorevenseed formation factorsaswasreported byTurkand Hall (1980). Bord and Hartville (1998) citedthat under drought stress condition, seed number reduced in all plants, mainly because of the abscission of flowers and pods. 
Table 1. Number of podsplant ${ }^{-1}$ and number of seeds $\operatorname{pod}^{-1}$ of seven selected soybean genotypes as affected by drought

\begin{tabular}{|c|c|c|c|c|}
\hline \multirow[t]{2}{*}{ Genotypes } & \multicolumn{2}{|c|}{ Number of pods plant $^{-1}$} & \multicolumn{2}{|c|}{ Number of seeds pod ${ }^{-1}$} \\
\hline & Control & Drought & Control & Drought \\
\hline G00081 & 53.00 & $\begin{array}{c}47.67 \\
(90)\end{array}$ & 2.26 & $\begin{array}{l}1.70 \\
(75)\end{array}$ \\
\hline G00056 & 101.67 & $\begin{array}{c}43.67 \\
(43)\end{array}$ & 2.01 & $\begin{array}{l}1.57 \\
(78)\end{array}$ \\
\hline Shohag & 100.00 & $\begin{array}{c}44.33 \\
(44)\end{array}$ & 2.04 & $\begin{array}{l}1.21 \\
(59)\end{array}$ \\
\hline G 00078 & 75.67 & $\begin{array}{c}40.33 \\
(53)\end{array}$ & 1.97 & 1.19 \\
\hline G00137 & 87.00 & $\begin{array}{c}39.00 \\
(45)\end{array}$ & 1.42 & $\begin{array}{l}0.93 \\
(65)\end{array}$ \\
\hline G00035 & 104.00 & $\begin{array}{c}45 \\
(43)\end{array}$ & 1.84 & $\begin{array}{l}1.08 \\
(59)\end{array}$ \\
\hline G00060 & 57.00 & $\begin{array}{c}44.33 \\
(78)\end{array}$ & 1.88 & $\begin{array}{l}1.73 \\
(92)\end{array}$ \\
\hline $\operatorname{LSD}_{(0.01)}$ & & & & \\
\hline $\mathrm{CV}(\%)$ & & & & \\
\hline
\end{tabular}

Values presented in parentheses indicate percent of the control.

The effect of water deficit stress on the weight of 100 seed was statistically significant (Table 2). The highest seed weight both under control and water stress conditions was recorded in G00081 (14 g and $12.48 \mathrm{~g}$ ) and the lowest in G00037 (10.33 g and $7.0 \mathrm{~g}$ ). Relative weight of 100 seed of the genotypes ranged from $65 \%$ to $89 \%$ at water deficit conditions.

Table 2. 100-seed weight and grain yield plant ${ }^{-1}$ of seven selected soybean genotypes as affected by drought

\begin{tabular}{|c|c|c|c|c|}
\hline \multirow[t]{2}{*}{ Genotypes } & \multicolumn{2}{|c|}{ 100-seed weight $(\mathrm{g})$} & \multicolumn{2}{|c|}{ Grain yield plant $^{-1}(\mathrm{~g})$} \\
\hline & Control & Drought & Control & Drought \\
\hline G00081 & 14.00 & $\begin{array}{c}12.48 \\
(89)\end{array}$ & 8.63 & $\begin{array}{l}6.38 \\
(74)\end{array}$ \\
\hline G00056 & 13.99 & $\begin{array}{c}11.37 \\
(81)\end{array}$ & 7.95 & $\begin{array}{l}4.26 \\
(54)\end{array}$ \\
\hline Shohag & 12.42 & $\begin{array}{l}9.32 \\
(75)\end{array}$ & 11.64 & $\begin{array}{l}5.33 \\
(46)\end{array}$ \\
\hline G 00078 & 11.32 & $\begin{array}{l}8.80 \\
(78)\end{array}$ & 10.76 & $\begin{array}{l}5.23 \\
(49)\end{array}$ \\
\hline G00137 & 10.33 & $\begin{array}{l}7.00 \\
(68)\end{array}$ & 10.54 & $\begin{array}{l}4.48 \\
(43)\end{array}$ \\
\hline G00035 & 13.48 & $\begin{array}{l}8.82 \\
(65)\end{array}$ & 12.67 & $\begin{array}{l}4.91 \\
(39)\end{array}$ \\
\hline G00060 & 12.13 & $\begin{array}{c}10.66 \\
(88) \\
\end{array}$ & 8.24 & $\begin{array}{l}5.82 \\
(71) \\
\end{array}$ \\
\hline $\operatorname{LSD}_{(0.01)}$ & & & & \\
\hline CV (\%) & & & & \\
\hline
\end{tabular}

Values presented in parentheses indicate percent values to the control.

Highest relative weight of 100-seed was obtained from G00081 (89\%) followed by G00060 (88\%), G00056 (81\%), G00078 (78\%), Shohag (75\%) and G00137 (68\%); and it was lowest in G00035 (65\%). 
The reduction of the weight due to water stress was lower in G00081 $(11 \%)$ while that was higher in G00035 (35\%). Soybean yield is more sensitive to drought stress during the early reproductive stage (i.e. flowering to early pod expansion) than other developmental stages (Westgate and Peterson, 1993). In another experiment it was revealed that the effects of drought stress and cultivar were significant on fertile pod plant ${ }^{-1}$, seeds plant $^{-1}$, seed yield, hundred kernels weight, seeds pod ${ }^{-1}$ of soybean (Malekiet al., 2013).

The effect of water deficit stress on yield was statistically significant (Table 2). The highest yield under control condition was recorded in G00035 (12.67 g) while the lowest in G00056 (7.95 g). On the other hand, under water stress conditions, G00081 produced the highest yield (6.38 g) and the lowest was recorded from G00056 (4.26 g). Relative yield of the genotypes ranged from 39\% to $74 \%$ across water deficit conditions. Highest relative yield was obtained from G00081 (74\%) followed by G00060 (71\%), G00056 (54\%), G00078 (49\%), Shohag (46\%) and G00137 (43\%) and it was lowest in G00035 (39\%). The reduction of the yield plant ${ }^{-1}$ due to water stress was lower in G00081 (26\%), while that was higher in genotype G00035 (61\%) indicating that this genotype is susceptible. Drought induced yield reduction was alsoreportedinmany cropspecies, the extent of whichdepended upontheseverityanddurationof thestressperiod.In maize, water stress reducedyield by delayingsilking,thusincreasingtheanthesis-tosilkinginterval.Thistraitwashighlycorrelatedwithgrainyield, specificallyearandkernelnumberplant ${ }^{-}$

${ }^{1}$ (Cattivellietal., 2008). Followingheading,droughthadlittleeffectontherateof kernelfillinginwheat,butitsduration(timefromfertilizationtomaturity)wasshortenedanddryweightreduced at maturity(WardlawandWillenbrink,2000).Droughtstressin soybean reduced totalseedyield(Fredericketal.,2001).In the present study,thereductioninseedyieldunderwaterstress wasassociatedwithdramaticdecreaseinalltheseyield components. Supporting evidenceswere reported byLudlow and Mushow(1990). Theyattributed the reduction inseedyieldunderwaterstresstothe reduction innumberofpodsplant ${ }^{-1}$, numberofseedspod ${ }^{-1}$ and seed weight. Asletal.(2003)citedthatincreaseintheirrigationintervalresultedin thereduction intheseedyielddue to theincreasein thepercentage ofinfertileseeds.

\section{Conclusion}

From the above results, it may be concluded that wide range of variability of morpho-physiological parameters associated with water deficit stress tolerance was found in the soybean genotypes tested. Water deficit stress exerted inhibitory effects on dry matter accumulation and yield of soybean. G00081 showed a relatively higher water deficit stress tolerance while G00035 was susceptible in terms of dry matter accumulation and yield performance. It may be concluded that higher water deficit stress tolerance in G00081 was associated with higher water content in leaf, higher accumulation of proline and less reduction of leaf chlorophyll.

\section{Acknowledgement}

We are grateful to the Ministry of Education, Government of Bangladesh for funding the research.

\section{References}

Abass, S.M. and H.I. Mohamed. 2011. Alleviation of adverse effects of drought stress on common bean (Phaseolus vulgaris L.) by exogenous application of hydrogen peroxide. Bangladesh J. Bot. 41: 7583. 
Asl, K.K., D.MazaheriandS.A. Peighambari. 2003.Effect of four irrigation intervalson theseedyieldandquantitativecharacteristics of sunflowercultivars.IranianJ.Agric. Sci. 34(2):293-301.

Banon, S., J. Ochoa, J.A. Franco, J.J. Alarcon and M.J. Sanchez-Blanco. 2006. Hardening of oleander seedlings by deficit irrigation and low air humidity. Environ. Exp. Bot. 56: 36-43.

Bord, J.E. and B.G. Harville. 1998. Late-planted soybean yield response to reproductive source/sink stress. Crop Sci. 38: 763-771.

Canavar, O., K.P. Gotz, F. Ellmer, F.M. Chmielewskiand M.A. Kaynak. 2014. Determination of the relationship between water use efficiency, carbon isotope discrimination and proline in sunflower genotypes under drought stress. Aust. J. Crop Sci. 8(2): 232-242.

Cattivelli, L., F. Rizza, F.W. Badeck, E. Mazzucotelli, A.M. Mastrangelo, E. Francia, C. Mare, A. Tondelli and A.M. Stanca. 2008. Drought tolerance improvement in crop plants: an integrative view from breeding to genomics, Field Crops Res. 105: 1-14.

Cramer, G.R. and D.C. Bowman. 1993. Cell elongation control under stress conditions. In: Handbook of Plant and Crop Stress, M. Pessarakli (Ed.). Marcel Dekker, New York, pp.303-319.

Duzdemir, O., A. Kurunc and A. Unlukara. 2009. Response of pea (Pisumsativum) to salinity and irrigation water regime. Bulgarian J. Agril. Sci. 15(5): 400-409.

Escuredo, I.P., C. Arrese-Igor and M. Becana. 1998. Oxidative damage in pea plants exposed to water deficit or paraquat. Plant Physiol. 116: 173-181.

Farooq, M., A. Wahid, N. Kobayashi, D. Fujita and S.M.A. Basra. 2009. Plant drought stress: effects, mechanisms and management. Agron. Sustain. Dev. 29: 185-212.

Fenta, B.A., S.E. Beebe, K.J. Kunert, J.D. Burridge, K.M. Barlow, J.P. Lynch and C.H. Foyer. 2014. Field phenotyping of soybean roots for drought stress tolerance. Agron.J.4: 418-435.

Frederick, J.R., C.R. Camp and P.J. Bauer. 2001. Drought-Stress effects on branch and main stem seed yield and yield components of determinate soybean. Crop Sci. 41:759-763.

Gomez, A.A. and A.A. Gomez. 1984. Statistical Procedure of Agricultural Research. John Wiley and Sons. New York. pp.20-2015.

Gwathmey,C.O.and A.E. Hall. 1992. Adaptation to mid-season droughtofcowpea genotypeswith contrasting senescence traits. Crop Sci. 32: 773-778.

Hossain, M.M., X. Liu, X. Qi, H.M. Lam and J. Zhang. 2014. Differences between soybean genotypes in physiological response to sequential soil drying and rewetting. The Crop J. 2: 366-380.

Karimi, M. and A.B. Mohseni. 2013. Effects of osmotic stress on soybean varieties. J. Nov. Appl. Sci. 2(4): 101-105.

Kazi, B.R., F.C. Oad, G.H. Jamro, L.A. Jamali and N.L. Oad. 2002. Effect of water stress on the growth, yield and oil content of sunflower. Pak. J. Appl. Sci. 2: 550-552.

Khan, M.S.A. 2013. Evaluation of soybean genotypes in relation to yield performance, salinity and drought tolerance. A Ph. D Dissertation. Department of Agronomy, Bangabandhu Sheikh Mujibur Rahman Agricultural University (BSMRAU), Gazipur-1706, Bangladesh.

Lacerda, C.F., J. Cambraia, M.A. Oliva and H.A. Ruiz. 2001. Plant growth and solute accumulation and distribution in two sorghum genotypes, under $\mathrm{NaCl}$ stress. Rev. Bras. Fisiol. Veg. 13: 270-284.

Lavisolo, C. and A. Schuber. 1998. Effects of water stress on vessel size xylem hydraulic conductivity in VitisviniferaL. J. Exp. Bot. 49: 693-700.

Ludlow, M.M. and R.C. Muchow. 1990. A critical evaluation of traits for improving crop yields in water limited environments.Adv.Agron. 43: 107-153.

Maleki, A., A. Naderi, R. Naseri, A. Fathi, S. Bahamin and R. Maleki. 2013. Physiological performance of soybean cultivars under drought stress. Bull. Env. Pharmacol. Life Sci. 2(6): 38-44.

Martinez, J.P., S. Lutts, A. Schanck, M. Bajji and J.M. Kinet. 2004. Is osmotic adjustment required for water stress resistance in the mediterranean shrub Atriplexhalimus L. Plant Physiol. 161(9): 1041-1051. 
Moussa, H.R. 2011. Low dose of gamma irradiation enhanced drought tolerance in soybean. Bulg. J. Agric. Sci. 17: 63-72.

Nam, N.H., G.V. Subbaroa, Y.S. Chauhan and C. Johansen. 1998. Importance of canopy attributes in determining dry matter accumulation of pigeon pea under contrasting moisture regimes. Crop Sci. 38: 955-961.

Naresh, R.K., Purushottam, S.P. Singh, A. Dwivedi and V. Kumar. 2013. Effects of water stress on physiological processes and yield attributes of different mungbean (L.) varieties. African J.Biochem. Res. 7(5): 55-62.

Nayyar, H. and D. Gupta. 2006. Differential sensitivity of $\mathrm{C}_{3}$ and $\mathrm{C}_{4}$ plants to water deficit stress: association with oxidative stress and antioxidants. Environ. Exp. Bot. 58: 106-113.

Pace, P.F., H.T. Crale, J.T. Cothren and S.A. Senseman. 1999. Drought induced changes in shoot and root growth of young cotton plants. J. Cotton Sci. 3: 183-187.

Paclik, R.L., Sakova, and V. Curn. 1996. Reaction of different cultivars of Soybean subsp. oleifera to water stress. Fytotechnicka-Rada. 1: 55-62.

Pathan, M.S., J.D. Lee, J.G. Shannon and H.T. Nguyen. 2007. Recent advances in breeding for drought and salt stress tolerance in soybean. M.A. Jenks, P.M. Hasegawa, and S. M. Jain (eds). In: Advances in molecu-lar breeding toward drought and salt tolerant crops. Springer Nether-lands. pp.739-773.

Praba, M.L., J.E. Cairns, R.C. Babu and H.R. Lafitte. 2009. Identification of physiological traits underlying cultivar differences in drought tolerance in rice and wheat. J. Agron. Crop Sci. 195: 30-46.

Siddique, M.R.B., A. Hamid and M.S. Islam. 2001. Drought stress effects on water relations of wheat. Bot. Bull. Acad. Sin. 41: 35-39.

Singh, B.B., P. Hartmann, C. Fatokun, M. Tamo, S. Tarawali and R. Ortiz. 2003. Recent progress on cowpea improvement. Chronic Hort. 43: 8-12.

Terzi, R., A. Sağlam, N. Kutlu, H. Nar and A. Kadıŏlu. 2010. Impact of soil drought stress on photochemical efficiency of photosystem II and antioxidant enzyme activities of Phaseolus vulgaris cultivars. Turk J. Bot.34: 1-10.

Turk,K.J.and A.E. Hall. 1980. Drought adaptation of cowpea. IV:Influenceofdroughtonwateruseand relationwithgrowthandseedyield.Agron.J.72:440-448.

Uddin S., S. Parvin and M.A. Awal. 2013. Morpho-physiological aspects of mungbean (VignaradiataL.) in response to water stress. Int. J. Agric. Sci. Res. 3(2): 137-148.

Velu, G. andK.Palanisami.2002.Impactofmoisturestressongrowthandyieldof sunflower. Madras Agric. J. 88(10-12): 660-665.

Wardlaw,I.F. andJ. Willenbrink.2000. Mobilizationoffructanreservesand changesinenzymeactivities inwheatstemscorrelatewithwater stress duringkernelfilling,NewPhytol.148: 413-422.

WARPO. 2005. Annual Report, Water Resource Planning Organization. Dhaka, Bangladesh.

Westgate, M.E. andC.M.Peterson. 1993. Flower and PodDevelopmentinWater-Deficient Soybeans (GlycinemaxL.Merr.). J. Exp. Bot. 44(1): 109-117. 